\title{
Interpretação da Geologia e das Estruturas do Embasamento e do Grupo Barreiras no SSE do Estado da Bahia Empregando Dados de Campo, Imagens SRTM e Dados Aeromagnéticos
}

Thaís Gomes Santana, Bolsista ANP-Agência Nacional do Petróleo/UFBA; Luiz C. Corrêa-Gomes, CPGG-Centro de Pesquisa em Geologia e Geofísica/DCA-CEFET-BA; Edson Emanoel Starteri Sampaio, CPGG-Centro de Pesquisa em Geologia e Geofísica/UFBA

Copyright 2010, SBGf - Sociedade Brasileira de Geofísica Este texto foi preparado para a apresentação no IV Simpósio Brasileiro de Geofísica, Brasília, 14 a 17 de novembro de 2010. Seu conteúdo foi revisado pelo Comitê Técnico do IV SimBGf, mas não necessariamente representa a opinião da SBGf ou de seus associados. É proibida a reprodução total ou parcial deste material para propósitos comerciais sem prévia autorização da SBGf.

\section{RESUMO}

Este trabalho apresenta as relações existentes no SSE do Estado da Bahia entre as estruturas rúpteis (falhas e fraturas) do Grupo Cenozoico Barreiras (GB) e do embasamento representado pelos Orógenos Itabuna-SalvadorCuraçá pertencente ao Cráton de São Francisco (CSF) arqueano-paleoproterozoico e Araçuaí meso-neoproterozóico obtidas no campo, e os sistemas de falhas do embasamento e da plataforma continental adjacente mapeados através da interpretação de mapas aeromagnéticos. Essas relações foram comprovadas através do estudo combinado dos dados de campo, dos lineamentos estruturais obtidos nos mapas de modelo de terreno (SRTM) e geológico, e dos domínios e lineamentos magnéticos obtidos a partir de mapas magnéticos.

\section{INTRODUÇÃO}

O presente trabalho envolveu estudos geológicos e geofísicos. O geológico correspondeu ao estudo do Grupo Barreiras e do embasamento através dos dados de campo da imagem de modelo de relevo (SRTM) e do mapa geológico. Por outro lado, na Geofísica aplicou-se os princípios da Física no estudo do interior da terra. Portanto, as medidas magnéticas foram influenciadas pela distribuição interna (de aspectos tais) como profundidade, tamanho, litologia, estratigrafia, contexto estrutural, dentre outros. A análise dessas medições revelou como os aspectos supracitadas, na área em estudo, variaram vertical e lateralmente.

Os dados de campo pertencem ao Projeto Neotectônica Litorânea do SSE do Estado da Bahia (Corrêa-Gomes, 2003) na parte do Grupo Barreiras que está situada no extremo sul do Estado da Bahia (Figura 1), variando em largura de $20 \mathrm{~km}$ a norte até $200 \mathrm{Km}$ a sul. Tal área se estende por cerca de $300 \mathrm{~km}$ de comprimento desde a cidade de Santa Cruz de Cabrália, até as proximidades da fronteira dos estados da Bahia e Espírito Santo. Após o processamento desses dados foram evidenciadas orientações de lineamentos estruturais rúpteis e dúcteis encontradas nos mapas de modelo de relevo, geológico e magnéticos segundo 4 padrões: NE-SW, E-W, NW-SE e $\mathrm{N}-\mathrm{S}$. Além de 4 campos de tensão principais que atuaram na região relacionados às orientações próximas de $\mathrm{N} 130^{\circ}-\mathrm{N} 140^{\circ}, \mathrm{N} 030^{\circ}-\mathrm{N} 040^{\circ}, \mathrm{N} 000^{\circ}-\mathrm{N} 010^{\circ}$ e $\mathrm{N} 090^{\circ}$ $\mathrm{N} 100^{\circ}$.

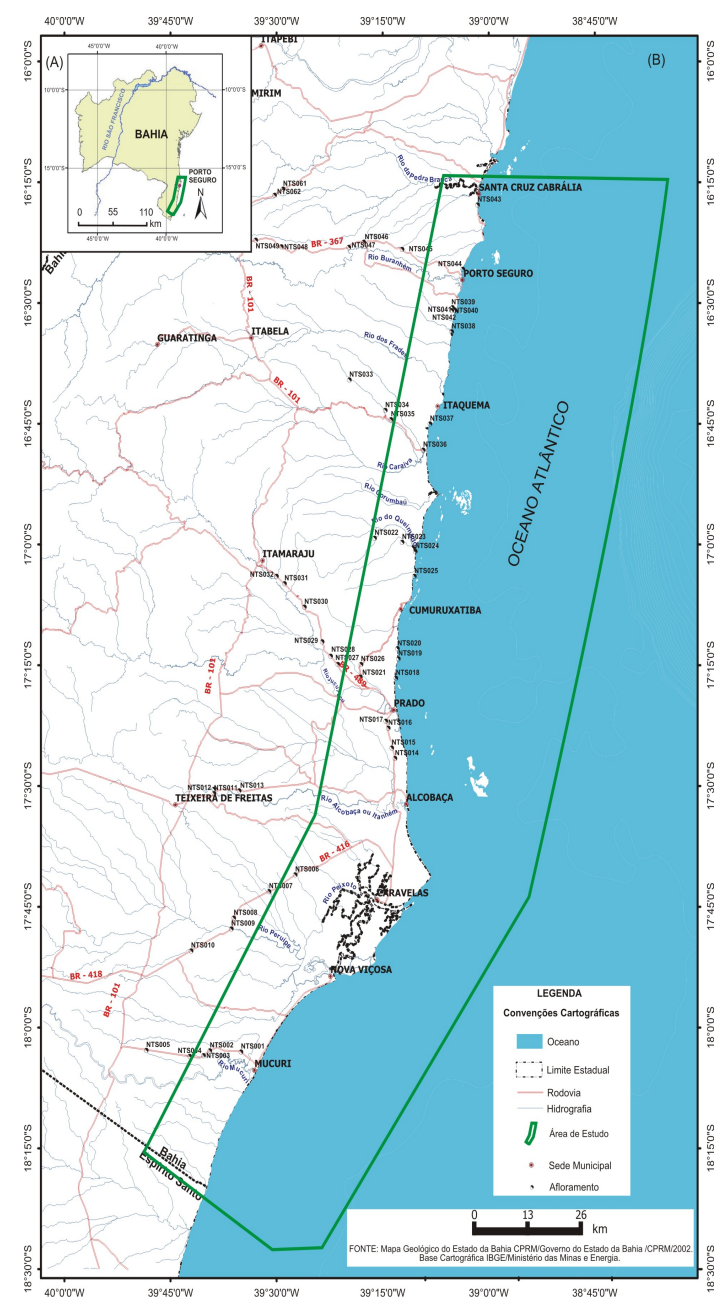

Figura 1: Localização da área estudada no Estado da Bahia indicada por linhas verdes no inset superior esquerdo $(A)$ e no mapa de localização da área ampliado (B). 
O trabalho completo de Geofísica compreendeu as etapas de planejamento, aquisição e processamento de medidas oriundas do método aeromagnético pela Empresa Fugro em 3 levantamentos regionais de reconhecimento realizados nas Bacias de Mucuri, Cumuruxatiba e Espírito Santo (Figura 2) entre as latitudes $16^{\circ} 14^{\prime} 00^{\prime \prime} \mathrm{e}$ $18^{\circ} 24^{\prime} 00^{\prime \prime}$ e numa área de $16.565 \mathrm{~km}^{2}$ ao longo do litoral, avançando cerca de $40 \mathrm{~km}$ mar adentro. Desta forma, foi possível localizar corpos e estruturas geológicas em subsuperfície através da medição de seus campos magnéticos anômalos.

Posteriormente, foi desenvolvida uma abordagem qualitativa, onde as imagens de anomalias magnéticas levaram a algumas interpretações, tais como: a região tem 4 domínios magnéticos; as províncias magnéticas distintas na área correspondentes ao Cráton de São Francisco e à Faixa Araçuaí são separadas pela Falha PoçõesTororó e Falha Planalto- Potiraguá; as intrusões, falhas e lineamentos equivalentes aos diques máficos e félsicos de caráter alcalino pertencente à Zona de cisalhamento de Itabuna - Itaju do Colônia (ZCIIC), aos traços do Orógeno Itabuna-Salvador-Curaçá e às estruturas que exercem controle tectônico dentro da Bacia de Cumuruxatiba; a profundidade das fontes anômalas indicando altos estruturais nos limites norte e sul da Bacia de Cumuruxatiba que corresponde a um baixo estrutural.

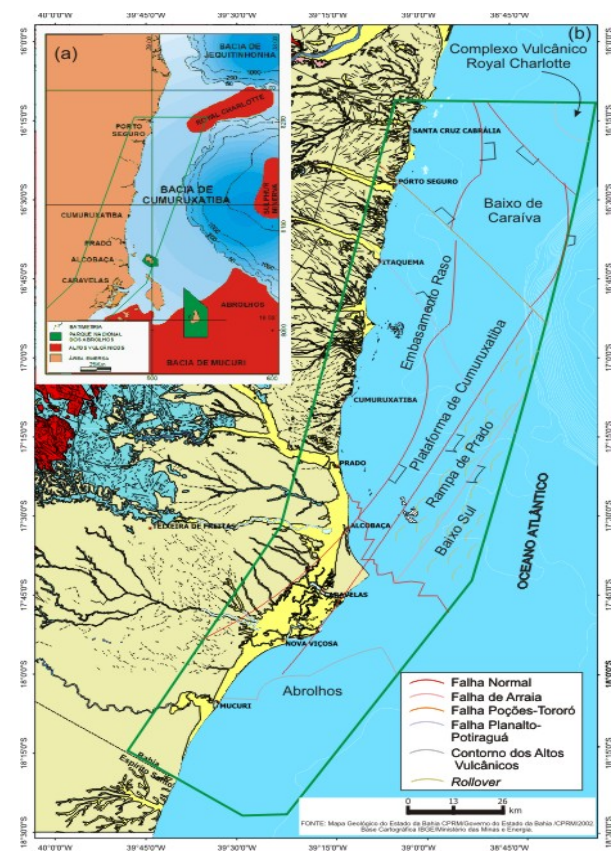

Figura 2: A localização da área estudada sobre as bacias presentes na região: Bacias de Jequitinhonha, Cumuruxatiba e Mucuri.Ela está indicada pelo retângulo no inset superior esquerdo (a), e no mapa com os principais componentes tectono - estruturais continentais e oceânicos do sul do Estado da Bahia com a indicação da área de estudo também em linha verde (b). Fonte: Modificado de (Rodovalho et al., 2003).

\section{METODOLOGIA/ PROBLEMA INVESTIGADO}

Inicialmente, um levantamento bibliográfico foi realizado sobre o estado da arte do Grupo Barreiras na região SSE do Estado da Bahia. Além de se levantar referências a respeito do método aeromagnético e sua aplicação na área de estudo.

Conforme o projeto Neotectônica, foram estudados 51 afloramentos nos quais foram medidos 4.815 planos de fraturas e falhas, a maioria desses planos apresentou mergulho subvertical. As orientações das falhas foram plotadas no programa Stereonett version 2.46 (Duyster, 2000) para obter rosáceas de direção, direção de mergutho e de isodensidade de freqüência para as estruturas planas.

Nos mapas de modelo de terreno (SRTM) (Figura 3) foram traçados os lineamentos estruturais a partir do contorno de vales e montanhas e das descontinuidades lineares do relevo que são potenciais indicadores de traços estruturais rúpteis (Figura 4). Posteriormente, no processamento de dados foi contada a quantidade de lineamentos e medido o somatório do comprimento deles para cada intervalo de medida. Sendo assim, foram produzidas duas rosáceas, uma de quantidade e outra de comprimento acumulado. O último procedimento também foi realizado com os lineamentos estruturais e magnéticos dos mapas de estruturas (Figura 5) e magnéticos (Figura 11), respectivamente.

Nos mapas magnéticos (Figuras 6, 7, 8, 9), de acordo com (Telford et al., 1976), a interpretação qualitativa foi feita separando primeiramente o mapa CMT em 4 zonas Magnéticas (ZM) por linhas contínuas brancas, cada uma tendo um comportamento distinto. A semelhança ou diferença do comportamento é julgada com base na disposição das curvas de contorno, na intensidade absoluta e relativa dos valores, nas derivadas, nos gradientes, amplitude do sinal analítico, continuações, etc. Em seguida, procurou-se caracterizar cada zona em termos de aspectos estruturais e litológicos, se possível com o emprego de informações geológicas. Para tal, nos mapas de Primeira e Segunda Derivada Vertical (PVD e SDV) foram traçados os lineamentos magnéticos comprovados e inferidos, ambos mais acentuados. Em seguida indicamos com uma seta, apontando do pólo positivo para o negativo, estruturas que se aproximam de dipolos isolados e linhas verticais de dipolos. O mapa de Sinal Analítico (SA) foi usado para delinear as formas dos corpos, separando-se regiões com valores altos do sinal analítico que indicam áreas com rochas e minerais mais magnéticos do que a encaixante. 


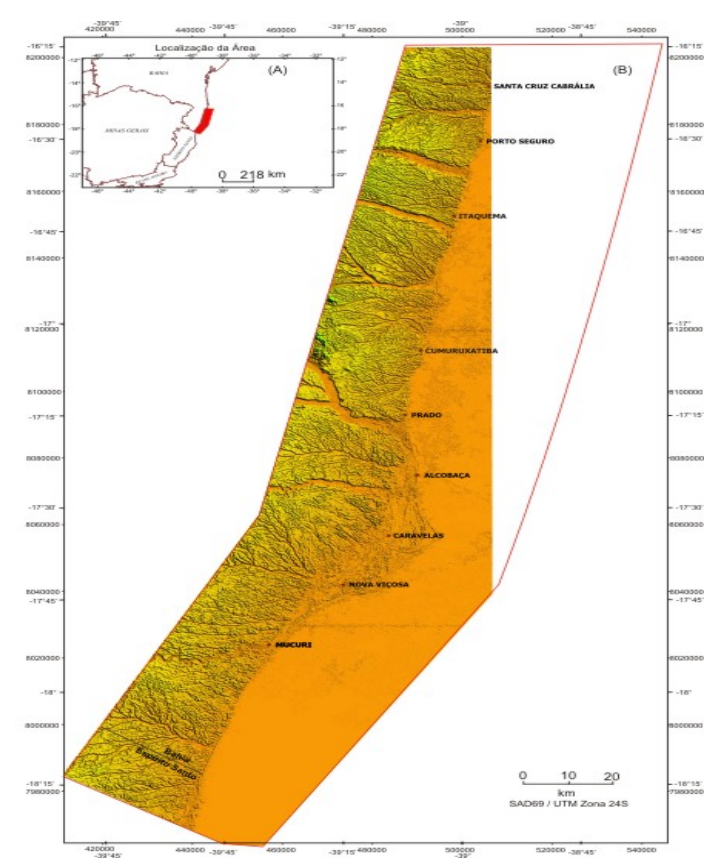

Figura 3: Localização da área estudada no Estado da Bahia indicada pelo retângulo no inset superior esquerdo (A) e na Imagem de Satélite do Relevo (B) obtida pelo projeto SRTM (Shuttle Radar Topography Mission - http://srtm.usgs.gov/ - NASA, NIMA, DLR e ASI), tirada com o satélite Landsat 7 no período de 2000 2001 e disponível gratuitamente pelo Site "http://www. relevobr.cnpm.embrapa.br/ba/index.htm/". As imagens pertencem a EMBRAPA Monitoramento por Satélite (Miranda, 2005).

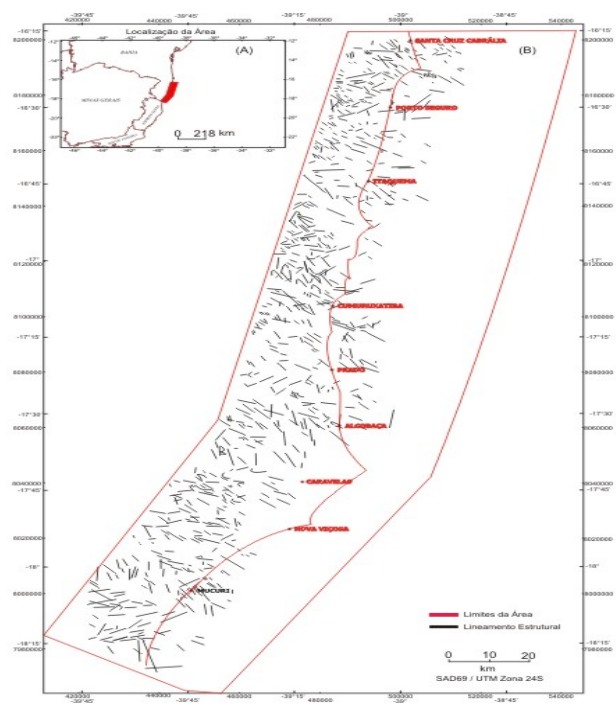

Figura 4: Localização da área de estudo no Estado da Bahia indicada pelo retângulo no inset superior esquerdo $(A)$ e nos lineamentos estruturais traçados a partir da Imagem de Satélite do modelo de Relevo (SRTM).

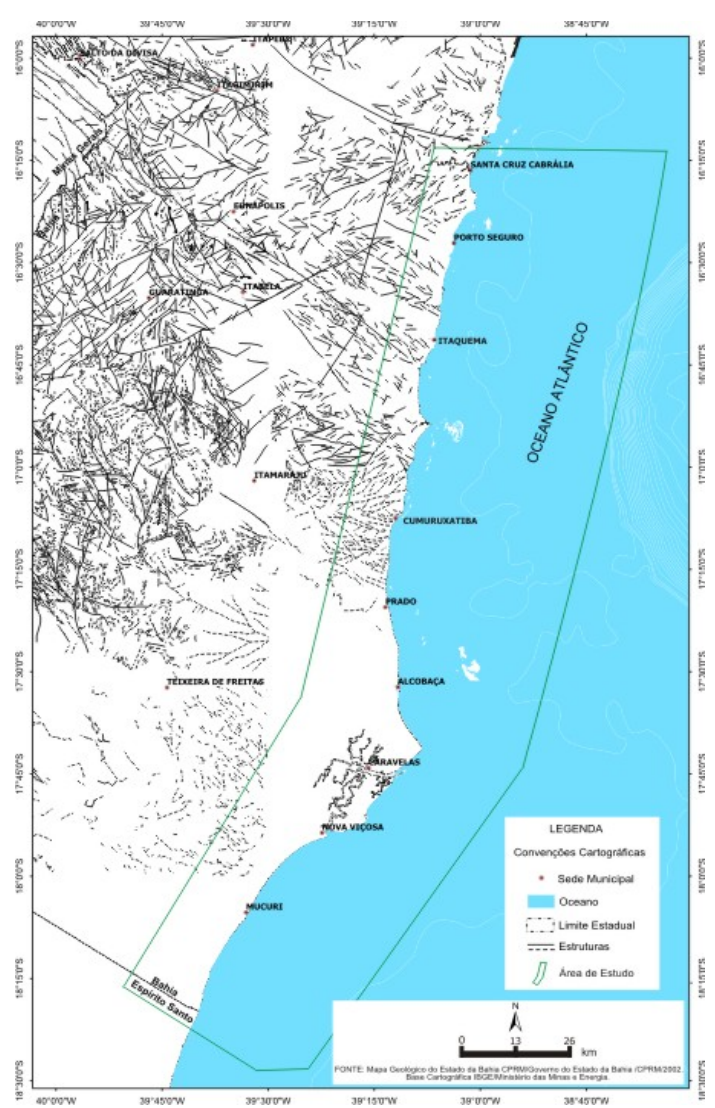

Figura 5: Mapa com os principais lineamentos estruturais dúcteis e rupteis da área estudada.

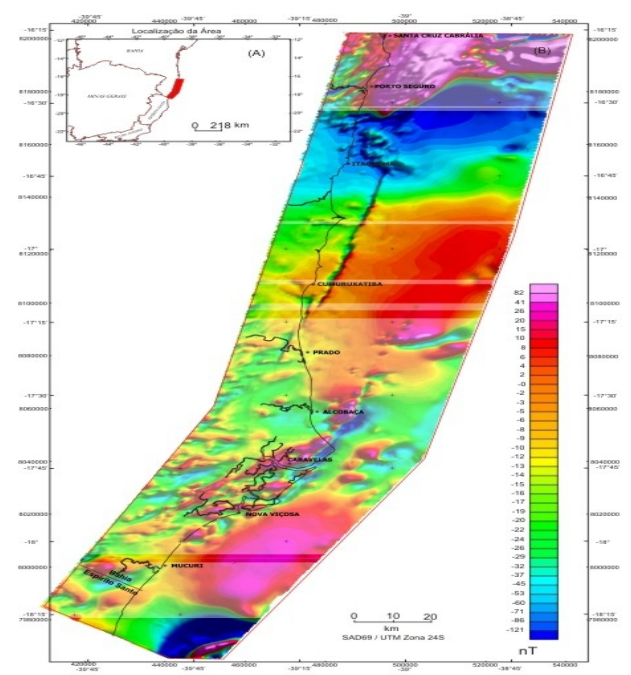

Figura 6: Localização da área de estudo no Estado da Bahia indicada pelo retângulo no inset superior esquerdo $(A)$ e no mapa da anomalia magnética de campo total (B), com o contorno continental delimitado e as localidades das principais cidades da área estudada. 


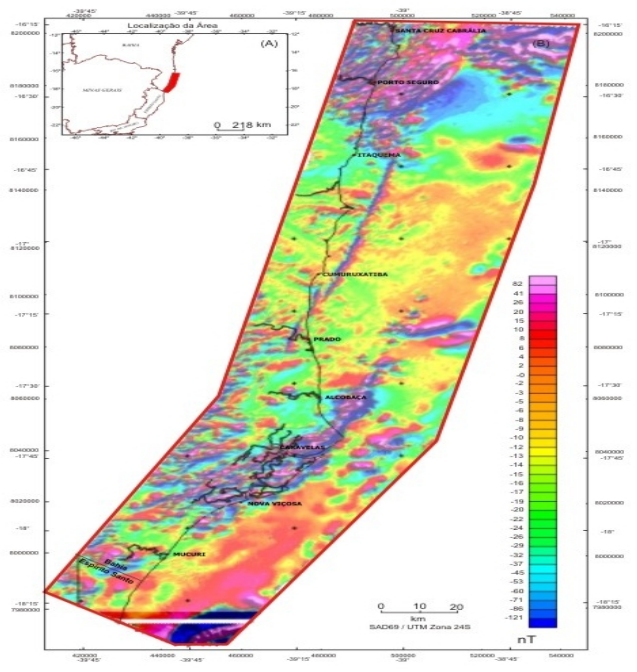

Figura 7: Localização da área de estudo no Estado da Bahia indicada pelo retângulo no inset superior esquerdo $(A)$ e no mapa da primeira derivada vertical da anomalia magnética de campo total $(B)$, com o contorno continental delimitado e as localidades das principais cidades da área estudada.

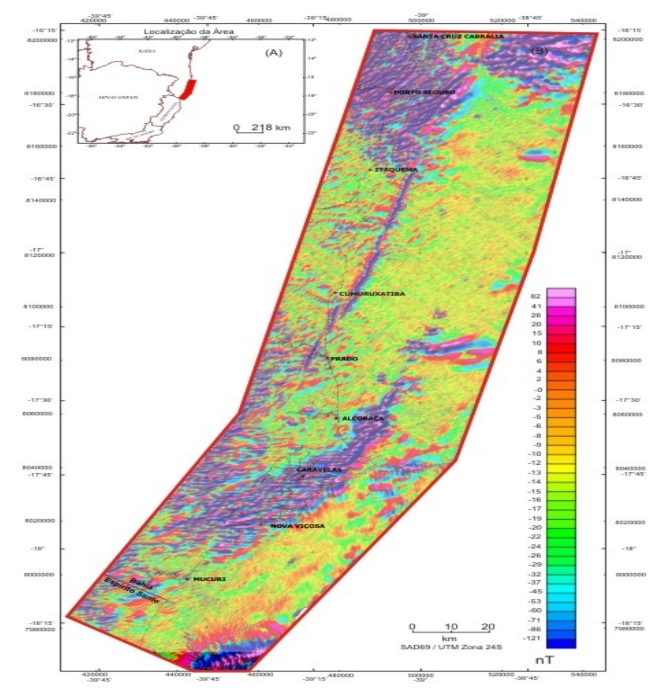

Figura 8: Localização da área de estudo no Estado da Bahia indicada pelo retângulo no inset superior esquerdo $(A)$ e no mapa da segunda derivada vertical da anomalia magnética de campo total $(B)$, com o contorno continental delimitado e as localidades das principais cidades da área estudada.

\section{RESULTADOS}

O tratamento estatístico dos dados mostra que o padrão estrutural da área é bastante diversificado (Figura 10), tanto no que diz respeito às direções dos lineamentos, quanto em relação aos padrões deformacionais rúpteis

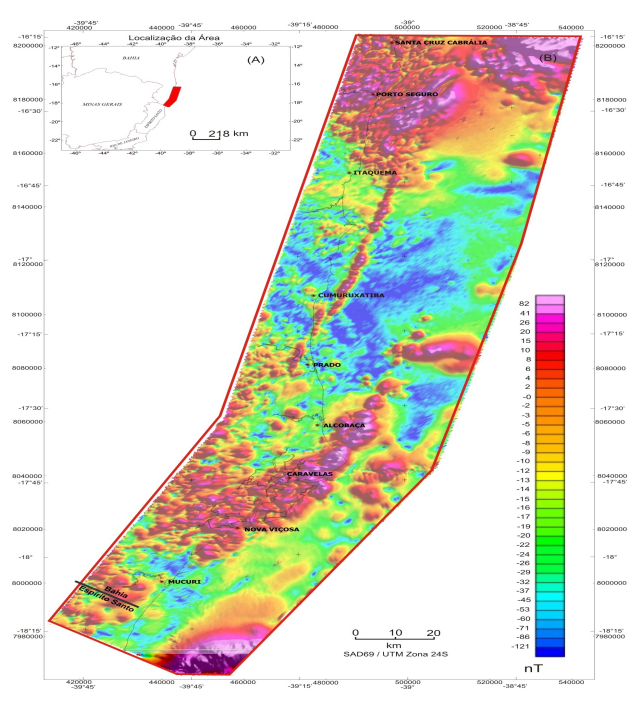

Figura 9: Localização da área de estudo no Estado da Bahia indicada pelo retângulo no inset superior esquerdo (A) e no mapa da amplitude do sinal analítico da anomalia magnética de campo total $(B)$, com o contorno continental delimitado e as localidades das principais cidades da área estudada.

e dúcteis com significativa presença de estruturas dobradas. A maioria dessas e das direções dos lineamentos identificadas na interpretação magnética são próximas às descritas em outros trabalhos referentes a região (Corrêa-Gomes, 2003), (Sampaio et al., 2004) e áreas relativamente próximas como o litoral sul (Lima, 2002) e as zonas de cisalhamento de Itabuna-Itaju do Colônia e de Potiraguá (Corrêa-Gomes et al., 2005).

As principais orientações das falhas e fraturas do Grupo Barreiras tiveram direções próximas à N $140^{\circ}, \mathrm{N} 090^{\circ}, \mathrm{N} 040^{\circ}$ e $\mathrm{N} 000^{\circ}$. O padrão $\mathrm{N} 140^{\circ}$ é marcante no mapa geológico e na Imagem de Satélite de Relevo (ISR). Na ISR, esta orientação tem direção próxima à do padrão de drenagem que corta a região. Tal padrão pode estar relacionado com a zona de cisalhamento de Potiraguá, devido a presença marcante da quantidade e do comprimento acumulado dessas medidas. Vale ressaltar que a direção da iluminação da ISR foi de N045 , evidenciando mais as estruturas com orientação ortogonal a esta. O padrão $\mathrm{N} 090^{\circ}$ foi observado no mapa geológico e trata-se da Faixa Araçuaí. O padrão N040 foi importante nos mapa geológico e magnético e corresponde aos traços da Zona de Cisalhamento de Itabuna-Itajú do Colônia (ZCIIC). O padrão N000 estar relacionado ao Orógeno Itabuna-Salvador-Curaçá. Considerando que a maior parte dos planos das falhas apresentam merguIho vertical, ou seja, essas estruturas são típicas de domínios tectônicos transcorrentes. Esses resultados indicam que essas estruturas foram reativadas do terciário ao recente segundo as principais orientações dos lineamentos magnéticos da região. 


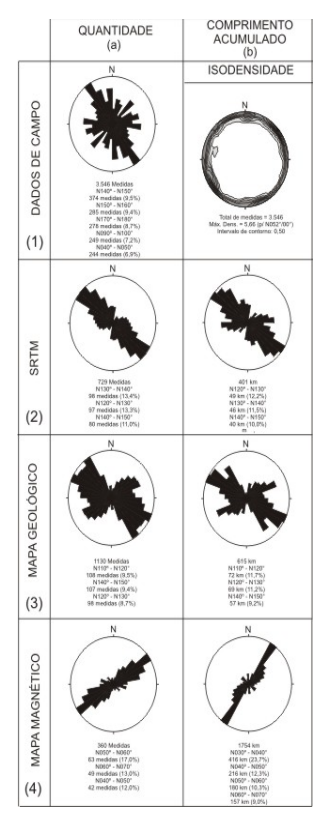

Figura 10: A figura mostra em (1), estereogramas de grandes círculos e densidade polar e rosácea com frequência de direção dos planos de falhas e fratura, obtidos a partir dos dados de campo; Diagramas em rosetas com frequência direcional dos lineamentos estruturais e magnéticos obtidos a partir dos mapas da SRTM (2), mapa estrutural (3) e mapas magnéticos (4) por quantidade de medidas (a) e por comprimento acumulado em km (b). Fonte: (Corrêa-Gomes et al., 2010).

Os padrões mais salientados nos mapas magnéticos compreendem os traços da Zona de Cisalhamento de ItabunaItajú do Colônia (ZCIIC), ao norte, e as falhas relacionadas a compartimentação tectônica da Bacia de Cumuruxatiba. Esses padrões tem menor importância nos resultados obtidos com os recursos ISR e levantamentos geológicos. Isso pode ter relação com as orientações e o espaçamento das linhas de voo. As linhas de voo na região foram orientadas $\mathrm{N} 045^{\circ} \mathrm{W}, \mathrm{N} 060^{\circ} \mathrm{W}$ e $\mathrm{N} 030^{\circ} \mathrm{W}$ e o espaçamento entre elas foi de $1 \mathrm{~km}$. Então, os lineamentos magnéticos observados nos mapas têm orientações principais próximas de $\mathrm{N} 040^{\circ} \mathrm{E}-\mathrm{N} 070^{\circ} \mathrm{E}$, coincidentemente ortogonais à orientação das linhas de controle como prediz a teoria do método magnético. Além disso, o grande espaçamento entre as linhas de produção podem ter auxiliado a minimizar mais ainda à aparição das estruturas magnéticas que foram pouco observadas e tem direções próximas das linhas de produção. Como as orientações dos lineamentos magnéticos mais destacadas podem ter sido beneficiadas pela configuração da aquisição dos dados aeromagnéticos, os resultados, se processados de outro modo, podem apresentar outra configuração.

Os mapas CMT, PDV, SDV e ASA serviram para identificar 4 domínios magnéticos que podem estar relacionados com a profundidade do embasamento ou com as di- ferentes propriedades magnéticas das principais unidades da região, tais como, os granitos e gnaisses. A zona ZM-2 e ZM-3 têm uma espessura maior de sedimentos que as zonas ZM-1 e ZM-4 por se tratar da Bacia de Cumuruxatiba que está delimitada por dois altos estruturais nos extremos norte e sul. No norte tem o limite entre ela e a Bacia Jequitinhonha, e no sul tem o limite dela com a Bacia de Mucuri. Esses limites correspondem a altos estruturais, tais como: as orientações das possíveis intrusões máficas e félsicas da ZCIIC com orientação NE-SW e parte do Banco Vulcânico Royal Charlotte com orientação E-W, ambos ao norte, e Abrolhos ao sul. A espessura dos sedimentos podem estar influenciando mais ainda na atenuação do sinal gerado pelo embasamento que já tem um sinal mais fraco em relação aos extremos por se tratar de um baixo estrutural.

A descontinuidade com direção SW-NE na região central separa longitudinalmente as partes leste e oeste da zona ZM-2 de intensidades diferentes por se tratarem da parte continental representada pelo GB na sua parte mais superficial, e do embasamento raso associado aos ortognaisses localizados ao norte do Complexo Mantiqueira sob a Plataforma de Cumuruxatiba. Essa descontinuidade pode ter se originado com a reativação tectônica das estruturas do embasamento, e ter sido preenchida por material pouco magnético correspondente aos sedimentos siliciclásticos do GB. Outra possibilidade é a disposição dos recifes de corais que acompanham o delineamento da costa. Neste caso, sob esses recifes ocorreu a deposição de sedimentos tércio-quaternários evidenciados por uma anomalia fraca (mapa CMT), e superficial (mapas PDV, SDV e SA).

As anomalias evidenciadas na Zona ZM-3 corresponde aos cordões litorâneos que ocorrem na zona costeira do extremo sul da bahia a partir do limite das Bacias de Cumuruxatixa e Mucuri. Assim, os sedimentos correspondentes às coberturas nessa região podem ter derivado diretamente do embasamento ou do Banco Vulcânico de Abrolhos, sendo depositados segundo o controle tectônico da Bacia de Cumuruxatiba. Esses sedimentos provavelmente são areias monazíticas e é constítuido por minerais com alta susceptibilidade magnética, tais como - titânio, ilmenita e magnetita. Outra sugestã dessa anomalia é que partes do embasamento pode estar num nível mais raso sob a Plataforma de Cumuruxatiba ou até mesmo aflorando, com orientação também seguindo esse controle tectônico.

\section{DISCUSSÃO E CONCLUSÕES}

Os estudos geológicos e geofísicos desenvolvidos na região mostram que importantes estruturas regionais foram herdadas do embasamento e reaproveitadas na estruturação rúptil das coberturas tércio-quaternérias, onde o GB cobre praticamente toda a área de estudo. $\mathrm{Na}$ aeromagnetometria, essas feições correspondem, principalmente, às intrusões de corpos máficos e félsicos com tendência alcalina situados no Segmento Sul do 


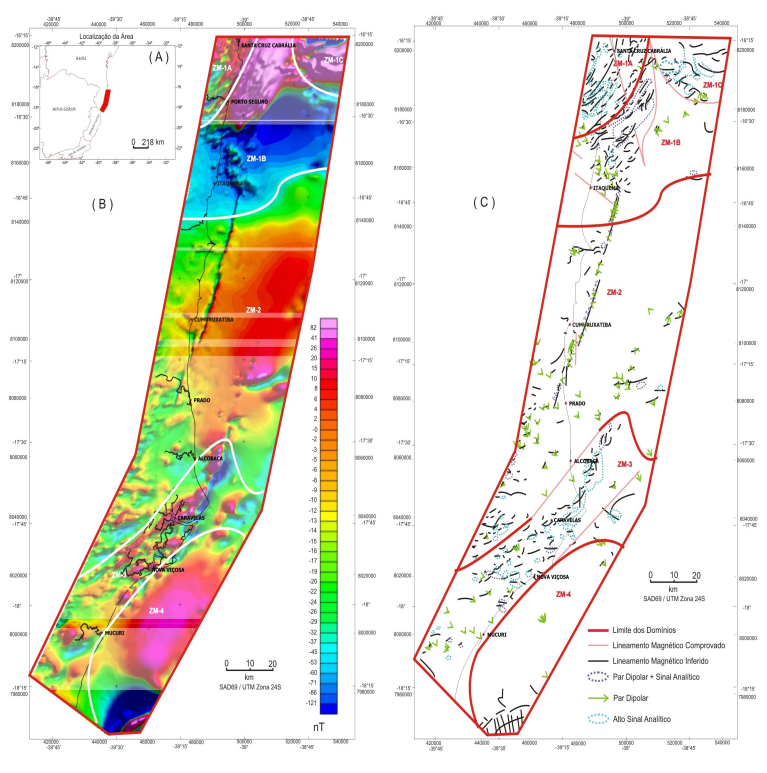

Figura 11: Localização da área de estudo no Estado da Bahia indicada pelo retângulo no inset superior esquerdo $(A)$ e domínios magnéticos da área de estudo sobre o mapa de contorno do campo magnético total, separados em zonas magnéticas (ZM) com base nos padrões das anomalias observadas (B). Além da interpretação magnética da área em termos de estruturas presentes, tais como, lineamentos magnéticos, dipolos magnéticos e regiões com alto sinal analítico (C).

Orógeno Itabuna-Salvador-Curaçá, associados à possível Zona de Cisalhamento de Itabuna-Itaju de Colônia (ZCIIC) que tem orientação $\mathrm{N} 040^{\circ}-060^{\circ}$. Elas se encontram nas zonas magnéticas ZM-1A, ZM-1B e ZM-1C. Além da compartimentação tectônica presente na Bacia de Cumuruxatiba presentes nas zonas magnéticas ZM2 e ZM-3. Apesar de os mapas geológicos e da SRTM assinalaram essas feições geológicas, outras estruturas referentes ao embasamento foram mais realçadas que estas. Elas são os traços das Zonas de Cisalhamento de Potiraguá, do Orógeno Itabuna-Salvador-Curaça e da Faixa Araçuaí que tem orientações $\mathrm{N} 120^{\circ}-150^{\circ}$, N $000^{\circ}$ $010^{\circ}$ e $\mathrm{N} 090^{\circ}-100^{\circ}$.

A interpretação qualitativa dos dados aeromagnéticos permitiu identificar unidades geológicas a partir dos grandes contrastes magnéticos observados na área, tais como, os altos vulcânicos Royal Charlotte e Abrolhos que estão localizados nas zonas ZM-1 e ZM-4, limitando a Bacia de Cumuruxatiba nos extremos norte e sul da área de estudo, respectivamente.

Inúmeras anomalias locais foram marcadas na região, como dipolos magnéticos e núcleos de sinal analítico. Elas estão associadas às chaminés de rochas básicas e ultamáficas e, dependendo das associações existentes, chaminés básico-alcalinas. Neste caso, tratam-se de anomalias pontuais e podem ser encontradas no limite das zonas magnéticas ZM-1B e ZM-2, e na parte NE e SW da zona magnética ZM-3. Essas anomalias podem ser pequenos corpos oriundos da cadeia vulcânica que originou Royal Charlotte e Abrolhos.

\section{AGRADECIMENTOS}

Ao CNPq pelo apoio financeiro ao projeto "Neotectônica Litorânea do SSE do Estado da Bahia", processo $n^{\circ}$ 478248/2001-6, à Petrobras pela bolsa de graduação entre 2008.1-2009.2 e pelo apoio financeiro ao Projeto Rifte com termo de cooperação UFBA/PETROBRAS/FAPEX $\mathrm{n}^{\circ}$ 0050.0029271.076.4, e à ANP-Agência Nacional do Petróleo- pela atual bolsa de mestrado.

\section{REFERÊNCIAS}

Corrêa-Gomes, L. C., Santana, T. G., Silva, I. C., and Pereira, L. R., 2010, Padrões de falhas e campos de tensão do terciário ao recente. O Grupo Barreiras no SSE do Estado da Bahia (em preparação).

Corrêa-Gomes, L. C., Dominguez, J. M. L., Barbosa, J. F. S., Silva, I. C. de, and Pinto, M. V., 2005, Relações entre orógenos, zonas de cisalhamento, quebra continental e deformações 3-d. a história tectônica da bacia sedimentar de Almada, Bahia: Revista Brasileira de Geociências, 35, 105-115.

Corrêa-Gomes, L. C., 2003, Projeto Neotectônica do SSE do Estado da Bahia. Relatório anual. Relatório Final. Pág. 60. Processo número: 478248/01-6 NV. CNPq.

Duyster, J. P., 2000, Stereografic projections and stereonets: Earth Sciences, USC.

Lima, C. C. U., 2002, Caracterização sedimentológica e aspectos neotectônicos do Grupo Barreiras no litoral sul do Estado da Bahia: Ph.D. thesis, Universidade Federal da Bahia, Salvador, Brasil.

Miranda, E. E. de, 2005, Embrapa monitoramento por satélite-Campinas. v.1. escala:1:250.000): Embrapa monitoramento por satélite-Campinas. v.1. escala:1:250.000):, Brasil em relevo. Disponível em http://www.relevobr.cnpm.embrapa.br., 2.

Rodovalho, N., Gontijo, R. C., Milhomem, P. de S., Lima, C. C. U. de, and Manso, C. L. de C., 2003, Bacias sedimentares brasileiras: Phoenix, 60.

Sampaio, A. R., Martins, A. M., Loureiro, H. C., Arcanjo, J. B., Moraes Filho, J. C., Souza, J. D. de, Pereira, L. H., Couto, P. A., Santos, R. A. dos, Melo, R. C. d., Bento, R. V., and Borges, V. P., 2004, Extremo sul da Bahia: Geologia e recursos minerais. arquivos abertos: CBPM e CPRM, Bahia.

Telford, W. M., Geldart, L. P., Sheriff, R. E., and Keys, D. A., 1976, Applied geophysics: Cambridge Universiy Press, New York. 